\title{
MICROSTRUCTURE-BASED 3D FE MODELING FOR MICRO CUTTING FERRITIC- PEARLITIC CARBON STEELS
}

\author{
M. Abouridouane* \\ Laboratory for Machine Tools \\ and Production Engineering \\ (WZL), RWTH Aachen \\ University \\ Steinbachstraße 19, 52074, \\ Aachen, NRW, Germany \\ Phone. +49 2418028176 \\ Fax. +49 2418022293 \\ Email.m.abouridouane@wzl. \\ rwth-aachen.de
}

\author{
F. Klocke \\ Laboratory for Machine Tools \\ and Production Engineering \\ (WZL), RWTH Aachen \\ University \\ Steinbachstraße 19, 52074, \\ Aachen, NRW, Germany \\ Phone. +49 2418027401 \\ Fax. +492418022359 \\ Email.m.abouridouane@wzl. \\ rwth-aachen.de
}

\author{
D. Lung \\ Laboratory for Machine Tools \\ and Production Engineering \\ (WZL), RWTH Aachen \\ University \\ Steinbachstraße 19, 52074, \\ Aachen, NRW, Germany \\ Phone. +49 2418027420 \\ Fax. +49 2418022293 \\ Email.m.abouridouane@wzl. \\ rwth-aachen.de
}

\section{ABSTRACT}

The mechanics of the cutting process on the microscopic level differ fundamentally from the conventional macro cutting. For example, the tool edge radius influences the cutting mechanism in micro machining significantly with regard to the effective rake angle, the minimum chip thickness, the dominance of ploughing, and the related elasto-plastic deformation of the workpiece material. These phenomena, known as size effects, have a profound impact on the cutting force, process stability, and resulting surface finish in micro cutting. Therefore, microstructural effects in microscale cutting require quite different assumptions to be made concerning underlying material behaviour during micro cutting and have led to the need for new modeling approaches to account for such effects.

This paper presents a three-dimensional finite element approach to incorporate microstructure into micro cutting simulation based on the concept of a representative volume element (RVE) and constitutive material modeling as well as using the Lagrangian formulation proposed in the implicit FE code Deform 3 ${ }^{\mathrm{TM}}$. Micro drilling and micro milling tests using solid carbide tools with different diameters $(\mathrm{d}=50 \mu \mathrm{m}-1 \mathrm{~mm})$ were performed on ferrite-pearlite two-phase steel AISI 1045 for the verification of the developed 3D multiphase $\mathrm{FE}$ computation model regarding chip formation, feed force, and torque. The developed 3D multiphase FE model was successfully used to predict size effects in micro cutting.

$\begin{array}{ll}\text { NOMENCLATURE } \\ \mathrm{A} & \text { initial yield stress } \\ \mathrm{B} & \text { hardening modulus } \\ \mathrm{C} & \text { strain rate sensitivity coefficient } \\ \mathrm{FE} & \text { finite element } \\ \mathrm{F}_{\mathrm{x}} & \text { cutting force in } \mathrm{x} \text { direction } \\ \mathrm{F}_{\mathrm{y}} & \text { cutting force in y direction } \\ \mathrm{F}_{\mathrm{z}} & \text { cutting force in } \mathrm{z} \text { direction } \\ \mathrm{JC} & \text { Johnson-Cook law } \\ \mathrm{SEM} & \text { Scanning Electron Microscope } \\ \mathrm{T} & \text { temperature } \\ \mathrm{a}_{\mathrm{e}} & \text { width of cut } \\ \mathrm{a}_{\mathrm{p}} & \text { depth of cut } \\ \mathrm{d} & \text { diameter } \\ \mathrm{f} & \text { total cutting feed } \\ \mathrm{f}_{\mathrm{z}} & \text { cutting feed per cutting edge } \\ \mathrm{k}_{\mathrm{f}} & \text { related feed force } \\ \mathrm{m} & \text { thermal softening exponent } \\ \mathrm{n} & \text { strain hardening exponent } \\ \mathrm{r}_{\mathrm{B}} & \text { cutting edge radius } \\ \mathrm{t}_{\mathrm{r}} & \text { related torque } \\ \mathrm{v}_{\mathrm{C}} & \text { cutting speed } \\ \mathrm{V}_{\mathrm{f}} & \text { feed velocity } \\ \sigma & \text { effective stress } \\ \varepsilon & \text { plastic strain } \\ \dot{\varepsilon} & \text { strain rate } \\ \mu & \text { Coulomb friction coefficient } \\ & \end{array}$




\section{INTRODUCTION}

Due to the advantages of micro technological solutions, such as small dimensions, low weight, energy efficiency, simultaneous functions integration and new applications, the product miniaturization is worldwide considered as key technology for the $21^{\text {st }}$ century. Therefore, micro machining is a central topic in product development in different fields of application as electronics, telecommunications, sensor technologies, optics, medical engineering, watch manufacturing, biotechnology and environmental engineering [1-3].

Although conventional machining and micro machining show many similarities, the cutting parameters of conventional machining, like cutting speed, feed, depth of cut and width of cut, cannot be offhand downscaled into the micro range due to size effects [4-9]. When the uncut chip thickness is on the same order as the material grain size, the workpiece material cannot any more be assumed as homogeneous and isotropic. Furthermore, the tool edge radius influences the cutting mechanism in micro machining significantly with regard to the effective rake angle and the ploughing effect [10-12].

In the past seven decades, conventional macro cutting mechanics have been amply investigated and various analytical, mechanistic, empirical and numerical models were developed to understand the thermo-mechanical interactions between workpiece material, tool and chip during the cutting process [13-22]. Most developed cutting models which are based on assumptions such as relative sharp tool edge radius and homogenous materials cannot be simply applied to micro cutting operations due to the above mentioned size effects. Especially, micro cutting of multiphase materials results in significantly varying cutting mechanisms and associated process response [23-26].

A popular tool in helping to explain the effects of microstructure during micro cutting is the use of finite element (FE) simulations. Due to the very complicated cutting process at the microscale and the higher modeling effort, most developed FE models for micro cutting heterogeneous materials are still limited at present to the two dimensional orthogonal cut and only give a qualitative prediction of simple plane strain cutting processes [27-30].

Based on the concept of a representative volume element (RVE) and constitutive material modeling, a 3D multiphase FE computational model is presented in this paper to simulate explicitly micro cutting ferritic-pearlitic carbon steels. The paper has three parts. First, a material characterization including the analysis of the microstructure and constitutive equations for each phase ferrite, pearlite and composite ferritic-pearlitic carbon steel C45 (AISI 1045) is discussed. Then, the development of the two phase 3D FE material model for steel C45 is described. Finally, the validation of the developed multiphase FE model using micro drilling and micro milling is performed.

\section{MATERIAL CHARACTERIZATION}

\subsection{Microstructure}

The materials used in this investigation are ferritic-pearlitic carbon steels C05, C45, and C75 with different carbon contents ranging from $0.05 \%$ to $0.75 \%$ but otherwise similar composition of other alloying elements. The materials were hot drawn, shaved, ground, normalized and supplied as steel bars with a diameter of $10 \mathrm{~mm}$. The microstructure of carbon steels consists of ferrite and pearlite, where the volume fractions depend primarily on the carbon content. Pearlite is a lamellar structure consisting of two phases, namely ferrite and cementite. For this purpose, steel C05 was assumed to be purely ferritic and steel C75 to be purely pearlitic. Quasi-static flow curves and one representative optical micrograph of each steel are shown in Fig. 1. In steel C05, ferrite, as white areas, is the dominating phase with a sparse distribution of pearlite, especially at grain corners. In steels C45 and C75 with higher carbon contents, pearlite is the dominating structure and ferrite is seen as white pockets between pearlite colonies (steel C45) and as grain boundary ferrite (steel C75). The carbon steels show a fairly similar hardening behaviour, while the difference in yield stress is large, see Fig. 1.

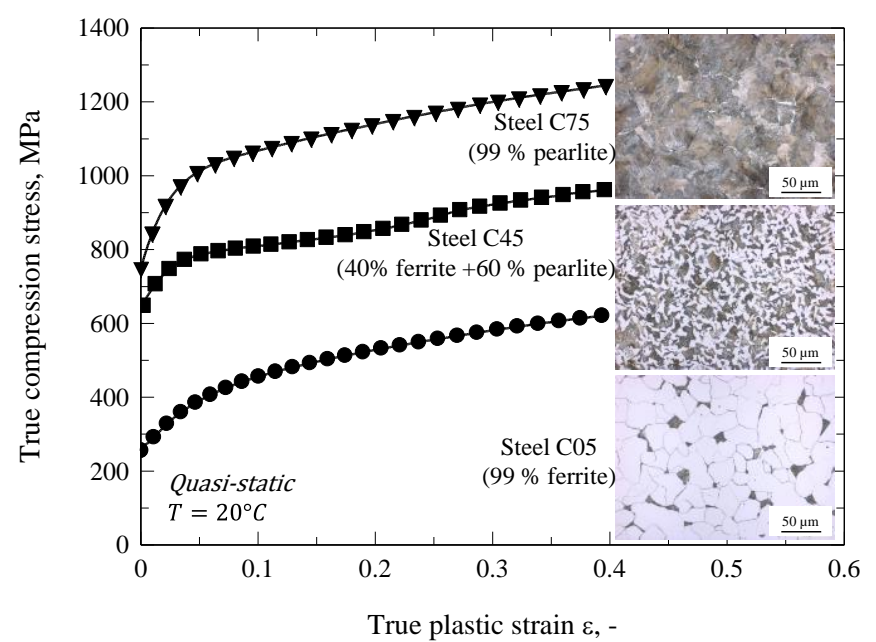

\section{Figure 1. Flow curves and microstructure of the investigated carbon steels.}

In this work, the steel's microstructure is characterized with respect to the volume fractions of the two structural constituents, ferrite and pearlite and the grain size of ferrite. The interlamellar spacing and the aspect ratio of pearlite are assumed to be the same for the investigated steels. The volume fractions of ferrite and pearlite of the steels were evaluated from micrographs and compared with the calculated values from the iron-carbon phase diagram. The determined volume fraction of pearlite in steels $\mathrm{C} 05, \mathrm{C} 45$, and $\mathrm{C} 75$ are $1 \%, 60 \%$, and $99 \%$, respectively, see Table 1 . The average grain sizes of ferrite were measured using the intercept method and presented in Table 1. The smaller ferrite grain size measured in steel $\mathrm{C} 45$ is expected 
since pearlite has grown in the material thereby decreasing the ferrite grains.

Table 1. Microstructural data.

\begin{tabular}{ccccc} 
Steel & $\begin{array}{c}\text { Carbon, } \\
\mathbf{w} \%\end{array}$ & $\begin{array}{c}\text { Pearlite, } \\
\boldsymbol{\%}\end{array}$ & $\begin{array}{c}\text { Ferrite, } \\
\boldsymbol{\%}\end{array}$ & $\begin{array}{c}\text { Ferrite grain } \\
\text { size, } \boldsymbol{\mu m}\end{array}$ \\
\hline C05 & 0.05 & 1 & 99 & 30 \\
C45 & 0.45 & 60 & 40 & 15 \\
C75 & 0.75 & 99 & 1 & - \\
\hline
\end{tabular}

\subsection{Constitutive material modeling}

To determine the mechanical flow behaviour of the carbon steels, uniaxial compression tests were performed on cylindrical specimens $(\varnothing 4 \times 4 \mathrm{~mm})$ of each steel at different strain rates. The compression tests with lower strain rates $(\dot{\varepsilon}<11 /$ s) were carried out using a numerically controlled hydraulic testing machine. The high strain rate tests with $\dot{\varepsilon}>10001 / \mathrm{s}$, were performed on a modified Split Hopkinson Pressure Bar [31].

The constitutive Johnson-Cook (JC) law was applied for the material modeling. The JC model is a strain rate and temperature dependent visco-plastic material model [32], which describes the thermo-mechanical material flow behavior (strain hardening, strain rate sensitivity, and thermal softening) over the entire strain rate and temperature range. The JC model uses the following equation for the equivalent flow stress:

$$
\sigma=\left(A+B \varepsilon^{n}\right)\left(1+C \ln \frac{\dot{\varepsilon}}{\dot{\varepsilon}_{0}}\right)\left[1-\left(\frac{T-T_{r}}{T_{m}-T_{r}}\right)^{m}\right]
$$

Where $\sigma, \varepsilon, \dot{\varepsilon}$, and T represent the equivalent flow stress, the equivalent plastic strain, the plastic strain rate and the absolute temperature, respectively. The JC parameters $\mathrm{n}$ (strain hardening exponent), $\mathrm{C}$ (strain rate sensitivity coefficient), and $\mathrm{m}$ (thermal softening exponent) describe the thermo-mechanical material behavior. The remaining JC material parameters are A (the initial yield stress), B (the hardening modulus), $\dot{\varepsilon}_{0}$ (reference strain rate), $\mathrm{T}_{\mathrm{r}}$ (room temperature), and $\mathrm{T}_{\mathrm{m}}$ (melting temperature).

The JC equation parameters A, B, n, and C were determined with help of the determined flow curves at room temperature of the correspondent steel and listed in Table 2. The thermal softening exponent $\mathrm{m}$ was identified by means of quasi-static compression tests at different temperatures $\left(20^{\circ} \mathrm{C}\right.$ $800^{\circ} \mathrm{C}$ ), see Table 2 . The reference parameters $\dot{\varepsilon}_{0}=0.002 \mathrm{~s}^{-1}$, $\mathrm{T}_{\mathrm{r}}=20^{\circ} \mathrm{C}, \mathrm{T}_{\mathrm{m}}=1500^{\circ} \mathrm{C}$ are specified.

Table 2. The parameter values of the JC equation for the carbon steels.

\begin{tabular}{cccccc} 
Steel & $\begin{array}{c}\text { A, } \\
\text { MPa }\end{array}$ & $\begin{array}{c}\text { B, } \\
\mathbf{M P a}\end{array}$ & $\begin{array}{c}\mathbf{n ,} \\
-\end{array}$ & $\begin{array}{c}\mathbf{C}, \\
-\end{array}$ & $\mathbf{m ,}$ \\
\hline $\mathrm{C} 05$ & 175 & 571 & 0.35 & 0.034 & 1.86 \\
$\mathrm{C} 45$ & 546 & 487 & 0.25 & 0.015 & 1.22 \\
$\mathrm{C} 75$ & 750 & 593 & 0.33 & 0.011 & 1.10 \\
\hline
\end{tabular}

Figure 2 shows a comparison between calculated flow stresses following Eq. 1 (continuous curves) and measured flow stresses from the compression tests (markers) at different strain rates and at a constant strain of $\varepsilon=0.1$. It is obvious that the $\mathrm{JC}$ material model describes the flow behaviour of the investigated carbon steels relatively well in the entire range of strain rates. In addition to the constitutive JC model, the linear rule-ofmixtures (ROM) is used to predict the mechanical behaviour of the two-phase steel C45. The flow stress data calculated by the linear rule-of-mixtures (dashed line, Fig. 2) show a quite good agreement with the experiment and the JC model. Consequently, the flow stress increases approximately linearly with the pearlite volume fraction. The flow curves of the two-phase carbon steel scale in a nice manner that JC equation parameters $\left(A_{c}, B_{c}, n_{c}\right.$, $\mathrm{C}_{\mathrm{c}}$, and $\mathrm{m}_{\mathrm{c}}$ ) can be determined for all carbon steels by means of the pearlite volume fraction $\mathrm{f}_{\mathrm{P}}$ (or carbon percentage) and JC parameters of Ferrite $\left(A_{F}, B_{F}, n_{F}, C_{F}\right.$, and $\left.m_{F}\right)$ and Pearlite $\left(A_{P}\right.$, $\mathrm{B}_{\mathrm{P}}, \mathrm{n}_{\mathrm{P}}, \mathrm{C}_{\mathrm{P}}$, and $\mathrm{m}_{\mathrm{P}}$ ), as shown Fig. 2. The micromechanical modeling based on the microstructure and constitutive material data is then possible, in order to predict the deformation behaviour. In the twophase FE material modeling, the steels C05 and C75 were used to describe the thermo-mechanical behaviour of the phases ferrite and pearlite, respectively.

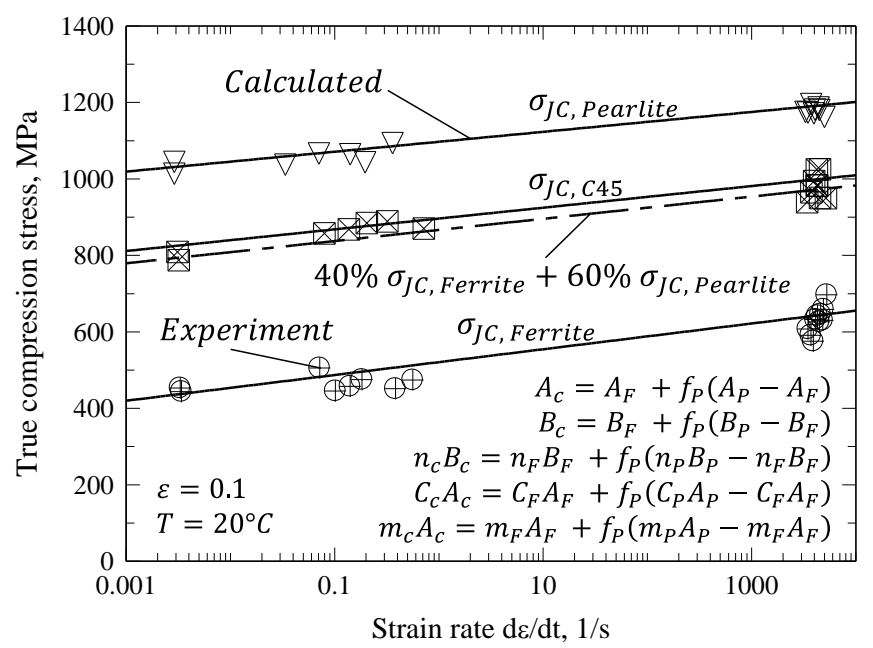

Figure 2. Constitutive description of the flow behavior of carbon steels.

\section{TWO-PHASE FE MATERIAL MODEL FOR STEEL C45}

\subsection{Modeling approach}

Based on the concept of a representative volume element (RVE), introduced by Hill [33], a new 3D two-phase FE material model was developed for the ferritic-pearlitic carbon steel C45. The RVE concept considers only a small material part that has the same average behaviour as a larger model. In the formulation of the FE material model, the microstructural data (phase volume fraction, ferrite grain size) and the 
constitutive description of the mechanical behaviour of each phase, determined in section 2, were applied. Grain orientation, inclusions, micro defects and phase transformations were not considered in this approach due to simplicity and computational efficiency. The major challenge of this approach was to generate a 3D RVE with a realistic morphology and sufficient number of grains, since the grain structures are 3D. In this context, some models like the Voronoi model [34] and micrograph model [35] have become established. The Voronoi algorithm utilizes a set of statistically distributed points (seeds) to partition space into region, i.e., Voronoi cells, one per point and hence to approximate a random microstructure. The Voronoi cells are created by considering each point and its nearest neighbours by application of a Delaunay triangulation algorithm. The micrograph model takes scanned pictures of the real material microstructure as input and creates a mesh. Basically, different phases are sorted out by their color.

The approach used in this work is developed at the WZL and based on the Voronoi model. It starts with a predefined $10^{-3}$ $\mathrm{mm}^{3}$ cubic (or cylindrical: $\varnothing 0.1 \times 0.1 \mathrm{~mm}$ ) FE mesh, as shown in Fig. 3. The grain generation occurs randomly (by means of the Mersenne Twister Algorithm) in consideration of the ferrite grain size (average value: $15 \mu \mathrm{m}$ ) and the ferrite - pearlite volume fractions $(40 \%$ - 60\%). Compared to the above mentioned models, this approach is very reliable, more efficient, computationally attractive, and the generation of the grain boundaries becomes very easy due to the predefined mesh. Figure 3 shows the generated RVE for C45 with 300 grains and an average grain size of $15 \mu \mathrm{m}$. Compared to the real microstructure in cross and longitudinal section, the two-phase 3D FE model provides a realistic 3D microstructure, as shown in Fig. 3.

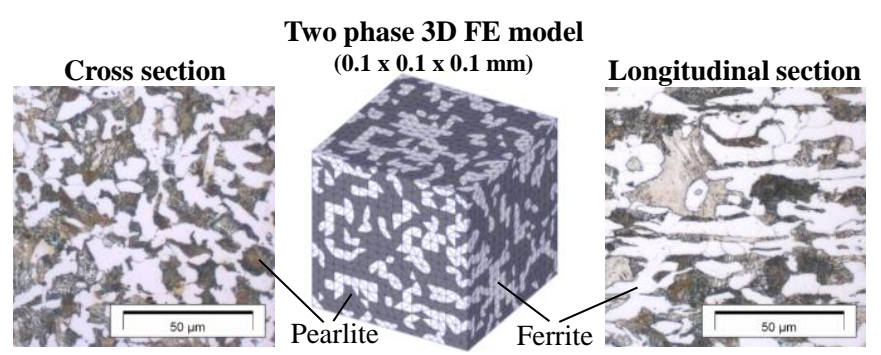

Figure 3. Generated 3D RVE for the two-phase carbon steel C45.

\subsection{Model verification}

To verify the developed 3D FE material model for C45, quasi-static compression, tension and shear tests were conducted on the investigated steel $\mathrm{C} 45$ at room temperature (compression specimen: $\varnothing 4 \times 4 \mathrm{~mm}$, tension specimen: $\varnothing 4 \times 20 \mathrm{~mm})$. The shear test was performed by means of a hatshaped specimen with a web thickness (shear zone) of $0.1 \mathrm{~mm}$ [31]. The same tests were simulated using the developed RVE and $\mathrm{FE}$ code Deform $3 \mathrm{D}^{\mathrm{TM}}$. It is assumed that the phases ferrite and pearlite behave in the same way in the two-phase material $\mathrm{C} 45$, as they do as single phases in C05 and C75 respectively. Fig. 4 shows a comparison between the experimental and computed flow curves under different loads. It is obvious that the developed multiphase 3D FE material model reproduces the mechanical behaviour of the real material C45 fairly well and can adequately be used for the simulation of micro cutting, provided that the RVE's volume is greater or equal to $10^{-3} \mathrm{~mm}^{3}$.

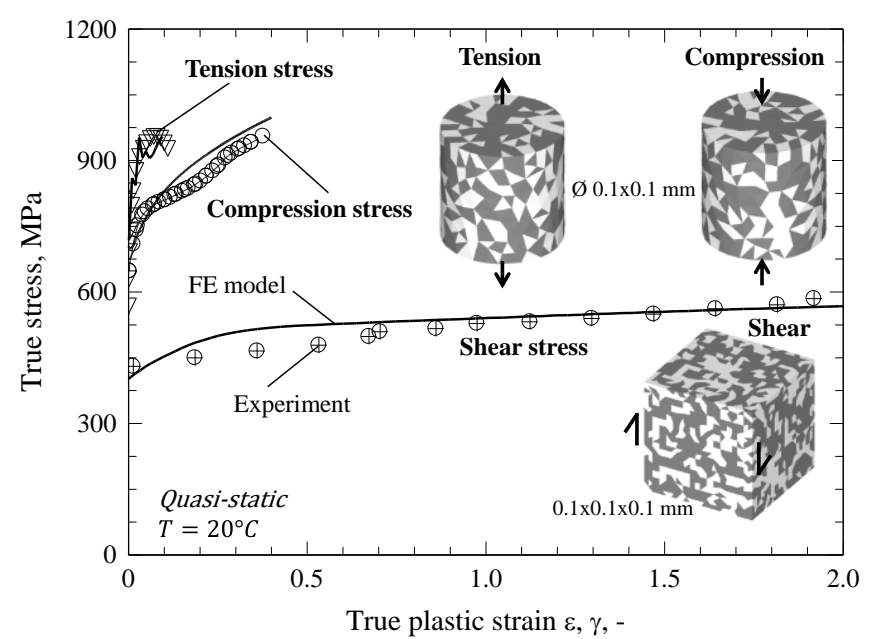

Figure 4. Verification tests of the developed 3D twophase RVE for C45.

\section{MICROSTRUCTURE-BASED 3D FE COMPUTATION MODEL FOR MICRO CUTTING}

\subsection{Multiphase FE modeling approach}

In this research work, a 3D thermo mechanically coupled two-phase finite element model of the micro cutting processes has been developed by using the commercial implicit FE code Deform-3 $\mathrm{D}^{\mathrm{TM}}$. The representation of tool and workpiece in the 3D FE simulation requires the input of geometrical, thermal and mechanical data. Since the geometry of the tool strongly influences the micro cutting process, the design of the selected micro tools has to be accurate. Only then, the FE model is able to predict real process behaviour during cutting. The micro tools geometries are designed by $\mathrm{CAD}$, whereas the detailed geometric parameters of the tool are made available by the tool manufacture.

The generated CAD models for the micro tools are then compared with the real micro tools. For more efficient computing, the volume of the modelled workpiece was selected as small as possible. The CAD models have been transferred in Deform 3D and meshed using 3D tetrahedron elements. After the meshing of workpiece, the two-phase microstructure was generated using the developed multiphase material model (see section above). Exemplarily, the generated 3D two-phase FE models for micro drilling and micro milling with $\mathrm{d}=1 \mathrm{~mm}$ are shown in Fig. 5. 


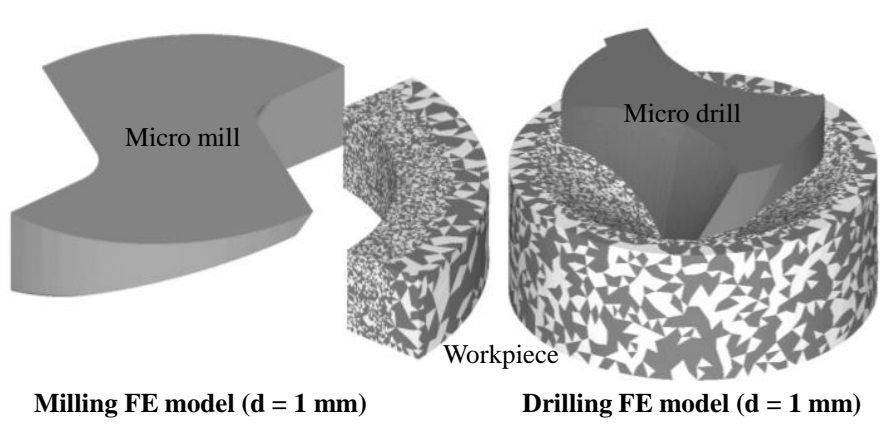

Figure 5. 3D two-phase FE models for micro drilling and micro milling.

\subsection{Boundary conditions}

The movement of the micro tools (rigid body with mesh) is specified by its translation and angular velocities in z-direction, while the workpiece (deformable) is constrained on the bottom and the round surfaces in the $\mathrm{x}, \mathrm{y}$, and $\mathrm{z}$ directions. Friction at the objects interfaces, tool-workpiece and chip-workpiece is governed by the Coulomb friction model $(\mu=0.2)$. For the thermal boundary conditions, conduction and convection of the generated heat are applied. The gap conductance and the thermal convection coefficient between two contacting surfaces are assumed to be $10^{7} \mathrm{~W} / \mathrm{m}^{2} \mathrm{~K}$ and $20 \mathrm{~W} / \mathrm{m}^{2} \mathrm{~K}$, respectively. The workpiece and tool temperatures are initially set to room temperature $\left(20^{\circ} \mathrm{C}\right)$. In order to adapt the energy balance in the modeled workpiece to the experiment, the nodes temperature at the bottom and the round surfaces are kept constant at a value of $20^{\circ} \mathrm{C}$. The implicit 3D simulation of the micro cutting process requires an enormous amount of CPU time. Therefore, parallel computing $(2 \times 3.2 \mathrm{GHz})$ are necessary to solve such a complicated problem.

\section{MICRO CUTTING VALIDATION TESTS}

\subsection{Micro cutting setup}

In order to validate the developed 3D multi-phase $\mathrm{FE}$ computation model, experimental and computational micro drilling and milling tests were carried out on the investigated steel C45 using different tool diameters (full carbide tools:

$\mathrm{d}=100 \mu \mathrm{m}-1 \mathrm{~mm})$. The micro cutting tests were conducted without the application of coolant on the ultra-precision CNC machining centre KERN Evolution (Fig. 6, position accuracy of $\pm 0.5 \mu \mathrm{m}$, maximum spindle speed of $160,000 \mathrm{rpm}$ ). The cutting speed $\mathrm{v}_{\mathrm{c}}=35 \mathrm{~m} / \mathrm{min}$, the feed $\mathrm{f}=0.012 \cdot \mathrm{d}$ and the drilling depth of $2 \bullet \mathrm{d}$ are the cutting parameters for the micro drilling tests and $\mathrm{v}_{\mathrm{c}}=60,80,100 \mathrm{~m} / \mathrm{min}$, the feed per cutting edge $\mathrm{f}_{\mathrm{z}}=0.01 \cdot \mathrm{d}$, the depth of cut $a_{p}=0.4 \cdot d$ and the width of cut $a_{e}=0.1 \cdot d$ for micro milling.

The cutting force and torque were measured using a Kistler dynamometer 9256B (working range of $\pm 250 \mathrm{~N}$, response threshold of $2 \mathrm{mN}$ ) and a highly sensitive torque sensor Kistler
9329A (working range of $\pm 1 \mathrm{Nm}$, response threshold of 30 $\mu \mathrm{Nm})$.

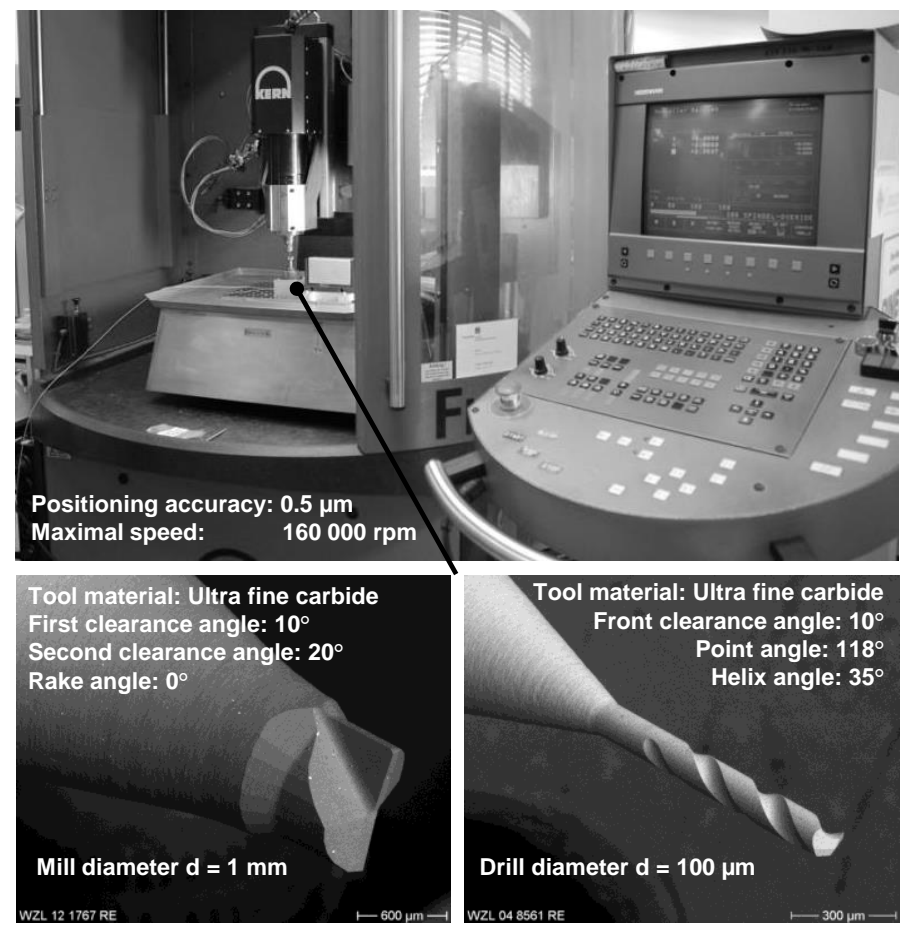

Figure 6. Ultra-precision micro machine tool.

In order to investigate the influence of the microstructure in micro drilling, two types of simulation were performed, one with isotropic and homogeneous material behavior and the second with the mixture material model discussed above. Furthermore, drill CAD models with sharp as well as rounded cutting edge were employed in the FE simulation to demonstrate the influence of the cutting edge rounding. Three size effects identified in micro drilling tests were predicted successfully with the developed two-phase 3D FE model.

\subsection{Prediction of the size effect of the microstructure}

The validation of the mixture FE model for micro drilling using a drill diameter of $\mathrm{d}=1 \mathrm{~mm}$ is represented in Fig. 7. The predicted values of the feed force and torque with the developed mixture model are in good agreement with the measured results (average deviation about 7\% and 3\% respectively). On the contrary, the deviation by the isotropic model, which takes no influence of the microstructure, is about $20 \%$, see Fig. 7 (b). A realistic prediction of the chip form was also obtained with the developed 3D multiphase FE model, as illustrated in Fig. 7 c). Scanning electron microscope (SEM) pictures show micro holes on the deformed chip, see Fig. 7 c). These holes could be attributed to the size of uncut chip thickness which was on the same order as the harder pearlite grains. This size effect could be reproduced by means of the multiphase FE model, as represented in Fig. 7 d). In the micro drilling simulation with $1 \mathrm{~mm}$ drill, the computed values of the strain rate are in the 
range of 0 to $30,0001 / \mathrm{s}$ and the maximum temperature calculated is about $150{ }^{\circ} \mathrm{C}$.

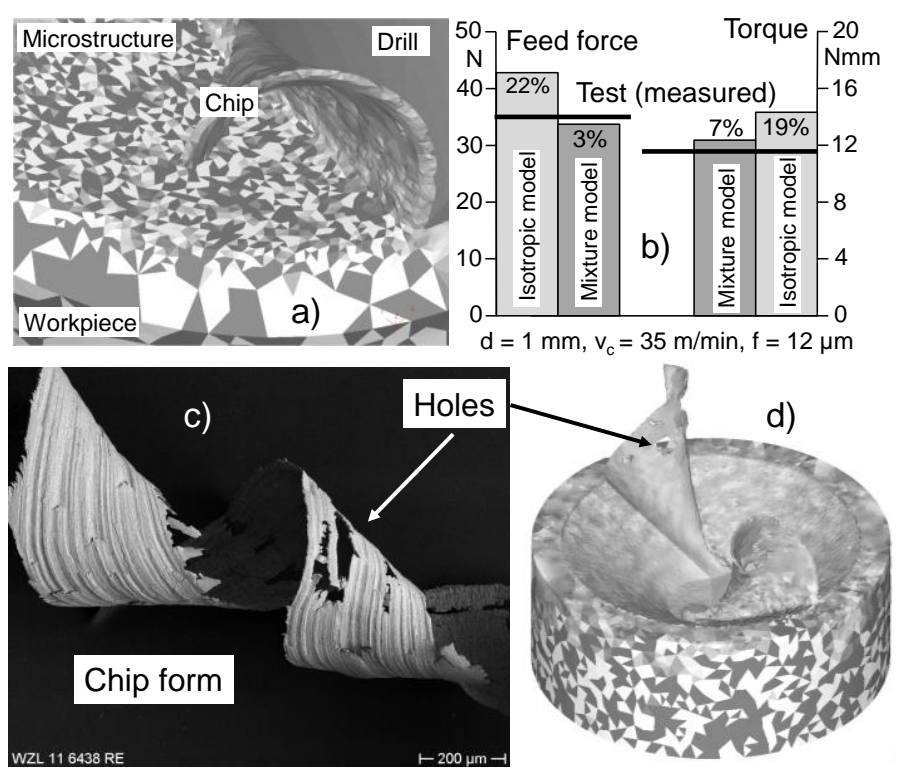

Figure 7. FE model validation - chip form in micro drilling C45 with $d=1 \mathrm{~mm}\left(r_{B}=1 \mu \mathrm{m}\right)$.

\subsection{Prediction of size effect of drill micro geometry}

To compare the obtained micro drilling results of this work with earlier macro drilling tests $(\mathrm{d}=1-3 \mathrm{~mm}$ and the same twist geometry) in the normalized steel C45 [23], the related feed force and torque to the cross section of the uncut chip $(\mathrm{d} \bullet \mathrm{f} / 2)$ are plotted versus drill diameters between $50 \mu \mathrm{m}$ und 3 $\mathrm{mm}$ in Fig. 8.

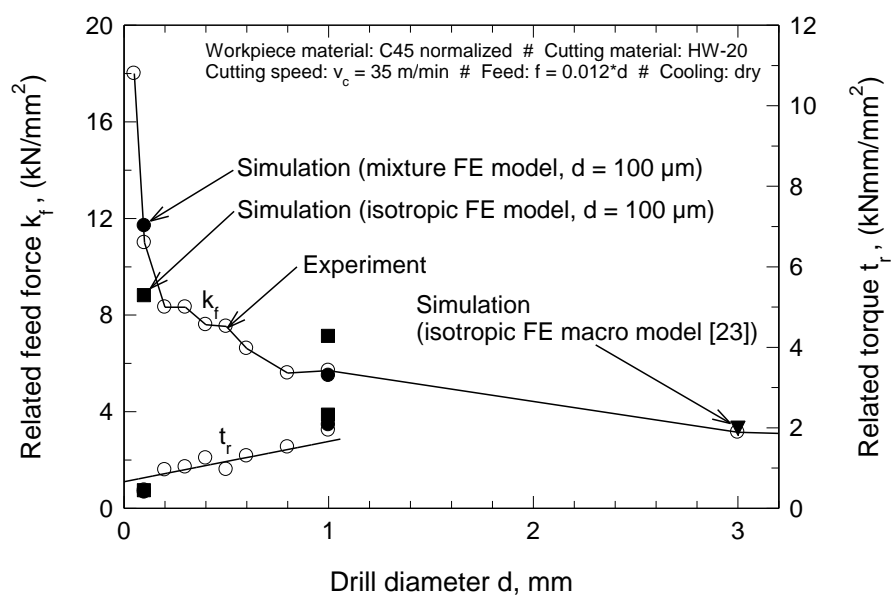

Figure 8. FE model validation - feed force and torque $\left(r_{B}=0.2 \mu \mathrm{m}\right.$ for $d=100 \mu \mathrm{m}, r_{B}=1 \mu \mathrm{m}$ for $\left.d=1 \mathrm{~mm}\right)$

A higher increase of the related feed force was observed by down scaling of the drill diameter in the micro range, see Fig. 8. This size effect on the related feed force can be attributed to the exponential growth of the ratio of chisel edge length to drill diameter. The technical qualified increase of the part of the chisel edge of micro drills is to ensure the rigidity and stability of the tool, leading to a significant influence on the micro drilling process reactions. The related torque behaves proportionately to the drill diameter in the micro range like in the case of the conventional macro drilling. The predicted results with the mixture FE drilling model for $d=100 \mu \mathrm{m}$ are in good agreement with the measured results (average deviation less than $10 \%$, see Fig. 8). On the contrary, the deviation by the isotropic model is up to $30 \%$. In this respect, the developed two-phase FE model for micro drilling can realistically predict the size effect of chisel edge length on the related feed force.

\subsection{Prediction of size effect ploughing in micro drilling}

SEM photographs of deformed chips in micro drilling tests on C45 with drill diameter $\mathrm{d}=100 \mu \mathrm{m}$ indicate a ploughing dominant cutting, as illustrated in Fig. 9 c) and d). For the prediction of this ploughing effect, when micro drilling with drill diameter $\mathrm{d}=100 \mu \mathrm{m}$, FE computations with the mixture FE model were performed using sharp and rounded cutting edges $\left(r_{\beta}=0 \mu \mathrm{m}\right.$ and $\left.r_{\beta}=0.2 \mu \mathrm{m}\right)$. These simulations were made in two successive steps: First, plunging the drill into the workpiece for one half of the feed without drill rotation and second, starting the drilling process.

Figures 9 a) and b) show the computed chip form after one half revolution of the drill when drilling with sharp and rounded cutting edge, respectively. Contrary to the simulation with sharp cutting edge, the deformed chip in front of the rounded main cutting edge became thinner and thinner until it disappeared. During simulation, the used FE program Deform $3 \mathrm{D}^{\mathrm{TM}}$ deletes elements with very small thickness. This computed effect demonstrates ploughing caused by the small ratio between the uncut chip thickness and cutting edge radius in micro cutting. In the same manner, ploughing effect could also be predicted with the isotropic FE model.

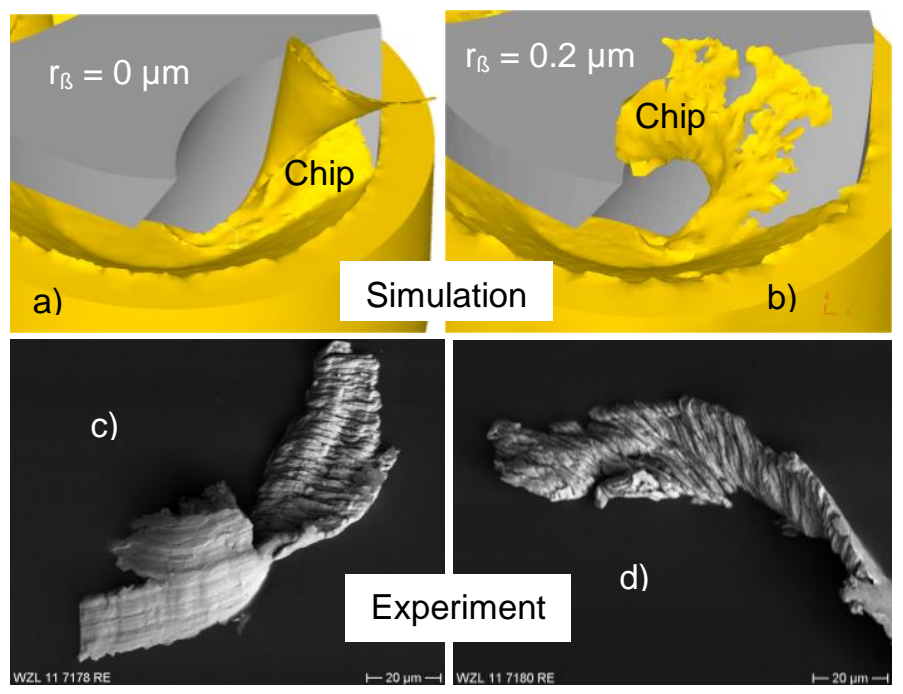

Figure 9. FE model validation - ploughing in micro drilling C45 with $d=100 \mu \mathrm{m}\left(v_{c}=35 \mathrm{~m} / \mathrm{min}, f=1.2 \mu \mathrm{m}\right)$ 


\subsection{Micro milling validation tests}

The validation of the developed two-phase FE model for micro down milling $\mathrm{C} 45$ with different cutting speeds $(60,80$ and $100 \mathrm{~mm} / \mathrm{min}$ ) and using a mill diameter of $\mathrm{d}=1 \mathrm{~mm}$ is shown in Fig. 10. The predicted cutting force components $F_{x}$ and $F_{y}$ (maximal values) with the microstructure-based $\mathrm{FE}$ model are in good agreement with the measured forces (average deviation about $10 \%$ ), see Fig. 10 a).The relatively higher deviation of the calculated cutting force component $F_{z}$ from the measured is due to the rigid body assumption of the micro mill without consideration of wear in the milling simulation. Furthermore, the geometry accuracy of micro mills used is insufficient leading to relatively higher values of the measured force components compared with the computation results.

The decrease of the cutting force with the cutting speed could moreover be reproduced in the simulation of micro milling C45, as illustrated in Fig. 10 a). This decline of the cutting force with the cutting speed is the result of the thermal material softening during cutting. Figures $10 \mathrm{~b}$ ) and $10 \mathrm{c}$ ) show a comparison between the computed and measured chip form exemplarily for micro milling with a cutting speed of 100 $\mathrm{m} / \mathrm{min}$. Obviously, a realistic chip formation in micro milling was also predicted by means of the multiphase FE model.
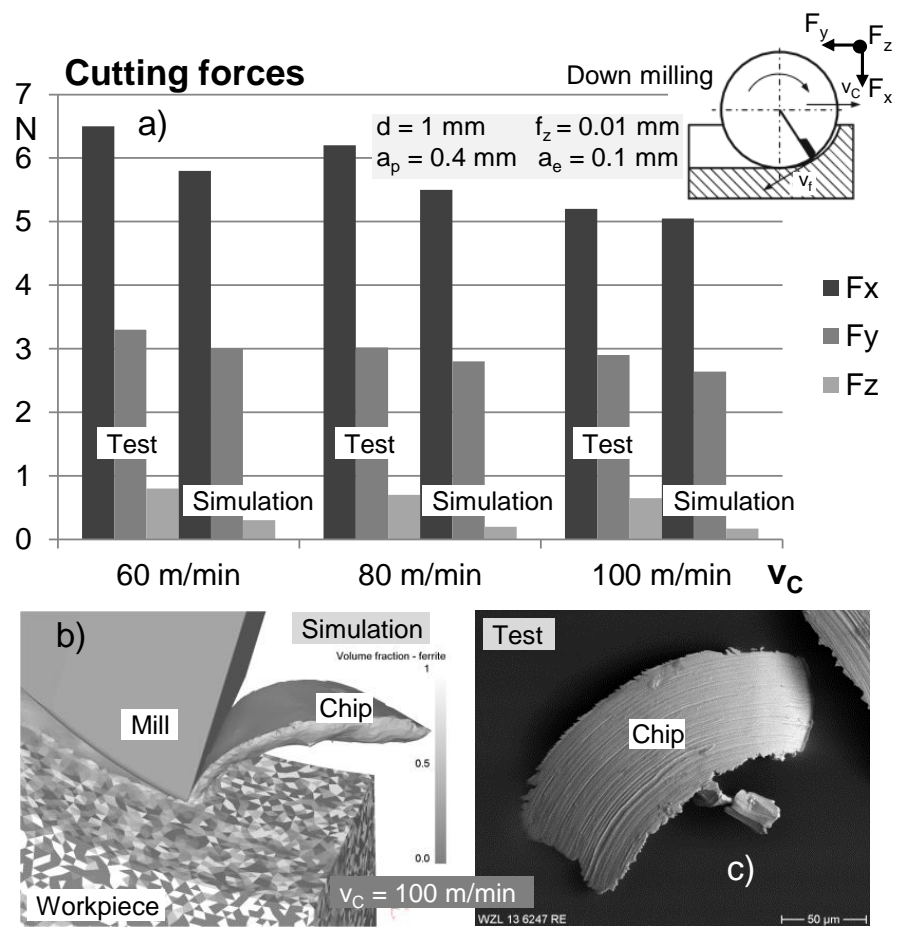

Figure 10. FE model validation - Cutting force and Chip form in micro down milling C45 with $d=1 \mathrm{~mm}$.

\section{CONCLUSIONS}

In the present research work, a microstructure-based 3D FE computation model is developed and successfully validated for micro cutting ferritic-pearlitic carbon steels. Some of the significant findings from this investigation can be summarized as follows:

- The microstructure morphology of carbon steel C45 and its phases ferrite and pearlite is evaluated experimentally

- By means of Split-Hopkinson-Pressure-Bar tests, a constitutive material law has been proposed to describe the thermomechanical material behavior at high strain rates

- Two-phase FE material model for steel C45 is developed and successfully validated under different loads

- A microstructure-based 3D FE computation model for micro cutting is worked out and validated for micro drilling and micro milling

- Three size effects identified in micro drilling test were predicted successfully with the developed multi-phase FE model.

\section{ACKNOWLEDGMENTS}

The results presented in this paper were determined within the framework of the Projects "3D FE Micro drilling simulation of multiphase materials" assisted by the research work of the DFG (Deutsche Forschungsgemeinschaft). The authors wish to record their gratitude to the DFG for its financial support.

\section{REFERENCES}

[1] Alting, L., Kimura, F., Hansen, H.N., Bissacco, G., 2003, "Micro Engineering", Annals of the CIRP, 52/2, pp. 635657.

[2] De Chiffre, L., Kunzmann, H., Peggs, G.N., Lucca, D. A., 2003, "Surfaces in Precision Engineering, Micro engineering and Nanotechnology", Annals of the CIRP, 52/2, pp. 561-577.

[3] Weule, H. et al., 2004, "International State of the Art of Micro Production Technology", Production Engineering, XI/1, pp. 29-36.

[4] Kopalinsky, E. M., Oxley, P.L.B., 1984, "Size Effects in Metal Removal Processes", Institute of Physics Conference Series, n70, pp. 389-396.

[5] Nakayama, K., Tamura, K., 1968, "Size Effect in MetalCutting Force", Journal of Engineering for Industry, pp. 119-126.

[6] Kountanya, R. K., 2002, "Process Mechanics of Metal Cutting with Edge radiused and worn Tools", Ph.D. Thesis, Univ. of Michigan.

[7] Klocke, F., Lung, D., Abouridouane, M., Sangermann, H., 2008, "Skalierungseffekte bei der Mikrozerspanung", VDI-Z Integrierte Produktion, 150, pp. 42-43.

[8] Cheng, K., Huo, D., 2013, "Micro-Cutting: Fundamentals and Applications", ISBN 978-0-470-97287-8 (cloth), John Wiley \& Sons, Oxford, UK.

[9] Liu, X., DeVor, R.E., Kapoor, S. G., 2004, "The mechanics of machining at the microscale: Assessment of the current state of the science", ASME J. Manuf. Sci. Eng., 126, pp. 666-678. 
[10] Dornfeld, D., Min, S., Takeuchi, Y., 2006, "Recent Advances in Mechanical Micromachining", Annals of the CIRP, 52/2, pp. 745-768.

[11] Klocke, F., Gerschwiler, K., Abouridouane, M., 2007 "Size Effects of the Tool Edge Radius on Specific Cutting Energy and Chip Formation in Drilling", Proceedings of the 2nd International Conference on New Forming Technology, Vollertsen, F. and Yuan, S. (Eds.), pp. 499509, Bremen.

[12] Kotschenreuther, J., 2008, "Empirische Erweiterung von Modellen der Makrozerspanung auf den Bereich der Mikrobearbeitung", Ph.D. Thesis, Univ. of Karlsruhe.

[13] Arrazola, P.J., Özel, T., Umbrello, D., Davies, M., and Jawahir, I.S., 2013, "Recent Advances in Modelling of Metal, Machining Processes," Annals of the CIRP, 62/2, pp. 695-718.

[14] Abdelrahman Elkaseer, A. M., Dimov, S.S., Popov, K.B., Minev, R., Negm, M., 2012, "Modeling the Material Microstructure Effects on the Surface Generation Process in Microendmilling of Dual-Phase Materials", J. Manuf. Sci. Eng. 134, 044501, pp. 1-10.

[15] Shekhar, S., Abolghasem, S., Basu, S., Cai, J., and Shankar, M. R., 2012, "Effect of Severe Plastic Deformation in Machining Elucidated via Rate-StrainMicrostructure Mappings" J. Manuf. Sci. Eng. 134, 031008, pp. 1-11.

[16] Koc, M., Özel, T., 2011, "Fundamentals of micromanufacturing", in Micro manufacturing: Design and Manufacturing of Micro-Products, John Wiley \&Sons, ISBN 978-0-470-55644-3, Chapter 1, pp. 1-24.

[17] M'Saoubi, R., Chandrasekaran, H., 2011, "Experimental study and modelling of tool temperature distribution in orthogonal cutting of AISI 316L, and AISI 3115 Steels", International Journal of Advanced Manufacturing Technology 56, pp. 865-877.

[18] Jin, X., Altintas, Y., 2011, "Slip-line field model of microcutting process with round tool edge effect" Journal of Materials Processing Technology, Volume 211, Issue 3, pp. 339-355.

[19] Outeiro, J.C., Pina, J.C., M'Saoubi, R., Pusavec, F., Jawahir, I.S., 2008, "Analysis of residual stresses induced by dry turning of difficult-to-machine", Annals of the CIRP, 57/1, pp. 77-80.

[20] Saldana, C., Shankar, M. R., Murthy, T. G., Huang, C., Gnanamanickam, E., Chandrasekar, S., 2008, "ZenerHollomon Parameter and Microstructure Prediction in Machining," Proceedings of the 11th CIRP Conference on Modeling of Machining Operations, Eds. - J. C. Heigel, S. P. Moylan and R. W. Ivester, pp. 129-137.

[21] Childs, T.H.C., 1998, "Material property needs in modelling metal machining", in: Proceedings of the CIRP International Workshop on Modeling of Machining Operations, Atlanta, Georgia, pp. 193-202.
[22] Astakhov, V.P., 1998, "Metal Cutting Mechanics", ISBN 10-0-8493-1895-5, CRC Press, Boca Raton, FL.

[23] Klocke, F., Gerschwiler, K., Abouridouane, M., 2009, "Size effects of micro drilling in steel", Production Engineering - Research and Development, 3/1, pp. 69-72.

[24] Denkena, B., Altan, T., Jivishov, V., Al-Zkeri, I., 2006, "Influence of Material Models Used in Finite Element Modeling on Predicted Scaling Effects in Machining", Prod. Engineering - Research and Development, 13/1, pp. 103-108.

[25] Imran, M., Mativenga, P. T., Withers, P.J., 2012, "Assessment of machining performance using the wear map approach in micro-drilling", International Journal of Advanced Manufacturing Technology, 59/1-4, pp. 119126.

[26] Zheng, L., Wang, C., Yang, L., Song, Y., Fu, .L, 2012, "Characteristics of chip formation in the micro-drilling of multi-material sheets", International Journal of Machine Tools \& Manufacture, 52, pp. 40-49.

[27] Chuzhoy, L., DeVor, R. E., 2003, "Machining Simulation of Ductile Iron and Its Constituents, Part 2: Numerical Simulation and Experimental Validation of Machining", ASME J. Manuf. Sci. Eng., 125/2, pp. 192-201.

[28] Park, S., Kapoor, S. G., DeVor, R. E., 2004, "Mechanistic Cutting Process Calibration via Microstructure Level Finite Element Simulation Model", ASME J. Manuf. Sci. Eng., 126/4, pp. 706-709.

[29] Simoneau, A., Ng, E., Elbestawi, M.A., 2007, "Grain Size and Orientation Effects When Microcutting AISI 1045 Steel", Annals of the CIRP, 56/1, pp. 57-60.

[30] Schulze, V., Zanger, F., Michna, J., Ambrosy, F., Pabst, R., 2011, "Investigation of the machining behavior of metal matrix composites (MMC) using chip formation simulation", 13th CIRP Conference on Modelling of Machining Operations, Sintra Portugal, pp. 20-29.

[31] EL-Magd, E., Abouridouane, M., 2006, "Characterisation, modelling, and simulation of deformation and fracture behaviour of the light-weight wrought alloys under high strain rates loading”, Int. J. Impact Eng. 31, pp.741-758.

[32] Johnson, G.R., Cook, W.H., 1983, "A constitutive model and data for materials subjected to large strains, high strain rates and high temperatures", Proc. 7th Int. Symp. on Ballistics, The Hague, Netherlands, pp. 541-547.

[33] Hill, R., 1963, "Elastic properties of reinforced solids, some theoretical principles", J. Mech. Phys. Solids, 11, pp. 357-372.

[34] Ghosh, S., Moorthy, S., 2004, "Three dimensional Voronoi cell finite element model for microstructures with ellipsoidal heterogeneities", Computational Mechanics, 34, pp. 510-531.

[35] Wojnar, L., 1999, "Image Analysis, Applications in Materials Engineering”, Boca Raton, FL: CRC Press. 